\title{
O exame nacional do "bom" professor sob um olhar reflexivo
}

\section{Reflecting upon the national examination of "Good" Teachers}

\author{
Raquel Silvano Almeida ${ }^{1}$, Luciana Grandini Gonçalves Cabreira²
}

\section{Resumo}

O que caracteriza um "bom" professor? Nasce-se? Torna-se? A ideia de professor como uma profissão vocacionada coloca em questão a formação docente que vem sendo tema de inúmeros estudos acerca dos cursos de graduação em Licenciatura disseminados pelo país. Rios (2001), quando propõe uma reflexão sobre um ensino de qualidade que ultrapasse a visão meramente técnica, lança um olhar à competência docente sob variados atributos que visam a um trabalho ético e competente. Mesmo considerando todas as competências conferidas ao "bom professor", discutidas por autores como Duarte (2001), Rios (2001) e Facci (2004), o objetivo primeiro deste estudo será o de refletir sobre os atributos que vêm sendo considerados na proposta do exame nacional docente defendida pelo MEC/INEP, sendo nomeado por alguns autores como o "Enem dos professores". Na análise do documento, encontramos uma série de valores que são atribuídos ao "bom" professor. Assim, adotando os pressupostos da abordagem qualitativa, por meio da técnica de pesquisa documental, serão levantadas questões sobre o que se pretende com este exame, considerando os aspectos que o documento atesta que caracterizam um "bom professor". Dessa forma, este trabalho pretende contribuir para uma reflexão acerca do papel a ser desempenhado por aquele que se espera do "bom" professor, levando-se em consideração os apelos pragmáticos, instrumentais e mercadológicos presentes no discurso que se anuncia no documento analisado.

Palavras-chave: Bom professor. Exame nacional docente. Enem dos professores.

\begin{abstract}
What characterizes a "good" teacher? Are you born? Do you become one? The idea of a teacher as a vocation profession calls into question the teacher education that has been the subject of numerous studies about undergraduate courses spread throughout the country. Rios (2001), when he proposes a reflection on quality teaching that surpasses the merely technical vision, throws a glance at the teaching competence under several attributes that aim at an ethical and competent work. Even considering all the competencies conferred on the "good teacher", discussed by authors such as Duarte (2001), Rios (2001) and Facci (2004), the first objective of this study will be to reflect on the attributes that have been considered in the proposal of the National Teacher Examination defended by the MEC / INEP, being named by some authors as the "ENEM of teachers". In documentary analysis, we find a number of values that are attributed to the "good" teacher. Thus, adopting the presuppositions of the qualitative approach, through the technique of documentary research, questions will be raised on what is intended with this examination, considering the aspects that the document attests that characterize a "good teacher". Thus, this paper aims to contribute to a reflection about the role to be played by what is expected of the "good" teacher, taking into account the pragmatic, instrumental and marketing appeals present in the discourse that is announced in the document analyzed.
\end{abstract}

Keywords: Good teacher. National teaching exam. Teachers' Enem.

\footnotetext{
1 Doutorado em Estudos da Linguagem pela Universidade Estadual de Londrina. Professora Adjunto A da Universidade Estadual do Paraná, campus de Apucarana. E-mail: raquel.almeida@unespar.edu.br

2 Doutoranda em Educação pela Universidade Estadual de Maringá -UEM
} 


\section{Introdução}

“[...] o desafio de ser professora, mais particularmente professora de professores, me traz todo dia a necessidade de olhar criticamente para a formação e a prática do aprendiz que é ensinante, ou que pretende sê-lo. Assim é que posso me ver melhor na prática de ensinante-aprendiz" (RIOS, 2001, p. 30).

A dimensão da formação de professores, conforme Rios (2001), implica em uma reflexão sobre a dicotomia ensinante-aprendiz que está presente durante toda a graduação em Licenciatura, nas disciplinas, nos estágios, na pesquisa. A articulação entre os diferentes saberes necessários à formação docente, as dimensões do processo formativo e a forma com que os estudantes pensam e problematizam o papel do professor na sociedade atual, trazem muitos desafios no âmbito da formação que, precisa atingir um patamar mais alto que o da lógica do mercado.

O bom professor nasce ou se desenvolve como tal? Este questionamento é alvo de debate há algum tempo nos cursos de formação inicial de professor/ educador (Licenciaturas). Historicamente, tem-se buscado delinear um conjunto de atribuições ou atributos e habilidades daquilo que é esperado, tanto por parte da sociedade como da escola do "bom professor".

Hoje, em uma sociedade neoliberal, em que ocorre uma "redefinição do conceito de produtividade do trabalho" e, consequentemente, "a individualização da responsabilidade [do sujeito] pela sua inserção no mercado de trabalho" (MACHADO, 2002, p. 10), é sabido que o "bom" professor precisa perfilar determinadas habilidades e competências para dar conta de responder a todas as demandas da sociedade e da escola, atreladas ao mercado econômico mundial.
Com o intuito de responder de forma emergente a essas demandas na educação brasileira, o Ministério da Educação, por meio do Instituto Nacional de Estudos e Pesquisas Educacionais Anísio Teixeira (INEP), busca inovar no campo da formação docente com a proposta do "Exame Nacional de Ingresso na Carreira Docente" que seria aplicado a partir de 2011.

Conforme Bruce (1993, p. 15), "adotar uma inovação é desencadear um processo no qual a incorporação a um sistema social dinâmico acelera mudanças nesse sistema, gera mudança na própria inovação, ou não causa nenhum efeito". Assim, o governo federal investe em um instrumento de avaliação inovador que norteie a melhoria na formação do professor e na qualidade de ensino da educação básica brasileira.

Desse modo, o documento intitulado "Referenciais para o Exame Nacional de Ingresso na Carreira Docente", elaborado pelo MEC/INEP no primeiro semestre de 2010 e lançado para consulta pública, apresenta a proposta de aplicação do exame nacional que dará "subsídios às redes estaduais e municipais para que estas possam aprimorar seus processos de seleção de professores e aumentar a periodicidade da contratação de professores".

Assim, o MEC/INEP estabelece uma matriz de referência do perfil do bom professor com base em critérios previamente definidos de avaliação do desempenho do professor por países como: Chile, Canadá, Austrália, Bélgica, Finlândia, Hong Kong, Japão, Holanda, Nova Zelândia, Cingapura e Coréia do Sul. O exame, ainda em desenvolvimento, se destinará àqueles que estejam em fase de conclusão de cursos de Licenciatura ou já licenciados e que tenham interesse em ingressar na carreira do magistério, inicialmente, na educação infantil e nas séries iniciais do ensino fundamental.

\footnotetext{
${ }^{3}$ Documento publicado no endereço eletrônico pelo Sistema de Consulta Pública sobre os referenciais para o Exame Nacional de Ingresso na Carreira Docente. "Por meio desta consulta pública, pretende-se submeter à sociedade os referenciais para a elaboração da matriz desse Exame, de modo a proporcionar a construção coletiva de um instrumento para avaliar os candidatos à docência no país. São aceitas contribuições pessoais ou institucionais - feitas pelo responsável pela instituição - e é possível opinar sobre todo o Exame ou apenas sobre algum dos temas propostos. Cada um decide a melhor forma de participar."
} 
Para uma análise e reflexão desse tema, é necessário que compreendamos, primeiramente, os aspectos que constituem uma sociedade neoliberal, a sua intervenção na educação e a consequente institucionalização de instrumentos avaliativos de inovação como é o caso do exame em questão: o "Enem dos professores" ${ }^{4}$. Assim, a análise da proposta e atributos conferidos ao "bom professor" é o objetivo deste estudo que vai se nortear pelos pressupostos da abordagem qualitativa com os recursos da pesquisa documental. Dessa forma, espera-se lançar luz sobre o que se pretende com essa proposta, tendo em vista o convite à discussão enquanto o documento está disponível no Sistema de Consulta Pública.

\section{O "Bom Professor" como Expoente de um Bom Ensino}

"[...] um discurso do poder se pronuncia sobre a educação, definindo suas metas, seus objetivos e seus conteúdos, ou seja, tomando as decisões. Professores e alunos acabam sendo excluídos do discurso pedagógico, não tendo outra opção a não ser assujeitarem-se livremente a esse pronunciamento" (CARDOSO, 1999, p. 50, grifo da autora).

Se pudéssemos perguntar às crianças os atributos que desejam ver nos professores que respostas teríamos? Pensar o papel do professor no ensino exige cuidado, uma vez que, as especificidades do trabalho docente vão além das qualificações técnicas, perfeitamente definidas, milimetricamente mensuráveis.

O trabalho docente em uma perspectiva históricocultural vai além das dimensões técnicas previstas para qualificar e adjetivar o "bom professor", uma vez que, sua prática implica em um caminho sinuoso até o conhecimento, por envolver a participação do aprendiz na construção do seu conhecimento.
Assim, considerar apenas o "bom professor" nesse processo é apagar o papel do estudante, regredindo talvez ao ponto em que este é considerado "tábula rasa" ou mero expectador nos processos de "ensinagem", é considerá-lo "a-luno", ou seja, aquele que ainda não foi contemplado com a luz do conhecimento. Eis aí uma dimensão importante que se perde no processo de ensino e aprendizagem quando se considera apenas o professor.

O professor como mediador nessa perspectiva cumpre o importante papel de transformar os conceitos cotidianos em conhecimento formal e científico em uma escala ascendente e, proporcionar a experiência com os conceitos científicos trazendoos para a vida dos estudantes em uma escala descendente, articulando saberes como Martins (1997) apregoa.

Nesse cenário, ainda precisamos considerar as vertentes do saber que se anuncia como algo novo na vida de uma pessoa que não para de aprender como Rios (2001) indica.

\begin{abstract}
Saber e sabor têm a mesma origem etimológica. Conhecer o mundo é sentir o seu gosto, que se experimenta não apenas pelo paladar, mas pelo conjunto dos sentidos, ainda assim insuficientes... Tomando como referência as dimensões do trabalho docente aqui apresentadas, podemos dizer, na verdade, que no ser do professor (e do aluno que ele procura educar) entrecruzam-se sentir, saber e fazer (RIOS, 2001, p. 24, grifo da autora).
\end{abstract}

Sentir, saber e fazer. Como dimensionar em termos técnicos e mensuráveis as dimensões do trabalho docente apresentadas por Rios (2001)? Parece que algumas dimensões do trabalho docente escapam a uma visão tecnicista. Dessa forma, uma reflexão se impõe sobre a prática docente e sua

\footnotetext{
4 "Mínimo denominador comum: ao investir na criação de uma matriz para o ingresso na carreira docente, „Enem dos professores” deverá definir critérios mais claros para a formação". (JARETA, 2011, p. 24 - 36).
} 
formação, uma vez que não é possível medir todas as competências do tão desejado "bom professor" ou reduzir todo o potencial deste a apenas uma lista de atributos.

Facci (2004, p. 223), quando descreve o trabalho do professor na mediação dos estudantes até o conhecimento reconhece seu papel no desenvolvimento das Funções Psicológicas Superiores - FPS - e destaca que "os conceitos científicos são assimilados por meio da colaboração sistemática entre o professor e a criança, colaboração esta em cujo processo ocorre o amadurecimento das FPS da criança, com o auxílio e a participação do adulto".

Dessa forma, os aprendizes contam com o professor para seguir desvendando o mundo e apreendendo, tendo os sentidos partilhados nessa aventura rumo ao conhecimento. Para Rios (2001, p.27) "o ensino é instância de comunicação" entre os diferentes atores sociais que circulam pelo cenário da escola. E a aula? Rios completa... "A aula não é algo que se dá, mas que se $f a z$, no trabalho conjunto de professores e alunos. [...] $\mathrm{O}$ fazer a aula não se restringe à sala de aula, está além de seus limites, no envolvimento de professores e alunos com a aventura do conhecimento, do relacionamento coma realidade" (RIOS, 2001, p. 27, grifo da autora).

O professor é um comunicador, um formador de opiniões, hábitos e atitudes. No convívio regular com seus alunos, ele orienta e identifica o caminho a ser seguido. Ele faz escolhas que se refletem em seus aprendizes. Mesmo nas situações educacionais mais restritas, quando do cumprimento de programas fechados - sem margens para interações mais democráticas e trabalho cooperativo - a forma como ele ensina (ou seja, tece mediações entre o conhecimento a ser trabalhado, suas posições diante desse conhecimento $\mathrm{e}$ as especificidades dos seus alunos) define valores (KENSKI, 2001, p. 101, grifo do autor).
Kenski (2001) tece atribuições ao professor não dimensionadas nos "Referenciais para o Exame Nacional de Ingresso na Carreira Docente", então como considerar o trabalho deste profissional que se vê desafiado diante das inúmeras tarefas que precisa cumprir além de lecionar?

O professor "é capaz de realizar interações $e$ intercâmbios entre linguagens, espaços, tempos e conhecimentos (pontes temporais, sociais, tecnológicas) diferenciados (KENSKI, 2001, p. 97, grifos do autor) estabelecendo diferentes níveis de interação e trocas, mediando o caminho até o conhecimento mais elaborado em uma sociedade como defende Duarte (2001). É papel do professor estabelecer de que forma a mediação irá acontecer organizando os conteúdos e atividades em uma ação didática que inclua o estudante, pois este também precisa estar presente na construção do saber, e nesse jogo de sentidos que vão sendo partilhados até alcançarem a internalização necessária, cabe ao professor disparar as estratégias que o consagraram na tarefa de ensinar. Assim, no diálogo estabelecido é que o conhecimento vai sendo partilhado, elaborado, internalizado nas diferentes dimensões do processo.

\begin{abstract}
O professor quando ensina não apresenta apenas informação. Ele seduz com a informação. Cria um clima favorável ou não a partir da maneira como apresenta e desenvolve o tema com seus alunos. Através das mais diversas práticas e linguagens comunicativas, o professor reinterpreta os dados da informação e os transforma em mensagem, que vai ser recebida e recodificada diferenciada e individualmente pelos alunos (KENSKI, 2001, p. 102, grifos do autor).
\end{abstract}

Kenski (2001) descreve o trabalho do professor com a propriedade de quem ensina formando professores. Assim, temos uma visão mais ampla do papel deste profissional na educação infantil e ensino médio. Trazendo mais subsídios para compreender a 
prática de quem está sempre aprendendo e refletindo sobre seu trabalho.

\section{O Surgimento de um Novo Mercado Educacional}

Parece indiscutível que a ação pedagógica consiste num fazer o real a partir do possível. A ação pedagógica depende de como nossos saberes determinam o possível e de como nossas práticas produzem o real. A educação, então, não seria outra coisa que a realização do possível. E isso tanto quanto possível é algo inscrito nas possibilidades de desenvolvimento das crianças como quando é algo projetado nas possibilidades de melhoria do mundo (LARROSA, 1998, p. 80).

Larrosa (1998) tenta definir a ação pedagógica, o fazer do professor dentro de um projeto de melhoria do mundo e, com um tom poético, inscreve o trabalho do professor como condição para se alcançar uma sociedade melhor, dentro do campo do possível, articulando esta dimensão a partir do real, ou seja, das condições que encontramos na sociedade.

Dentro da perspectiva neoliberal de competência e de qualidade total nas empresas, o sistema educativo, sob as condições predeterminantes do capital, absorve o que se poderia chamar de mercado educacional com "padrões de excelência".

Verificamos que os mesmos mecanismos e políticas empresariais se fazem presentes no sistema educacional por meio do estabelecimento de "rankings" do rendimento dos alunos, das competências dos professores e da hierarquização das instituições educacionais. $\mathrm{O}$ espírito de concorrência e de competição é institucionalizado no sistema educacional sob a anuência do Estado gestor.

Para Machado (2002, p. 20), “essas novas exigências do trabalhador [aluno e professor] ocorrem porque o mercado econômico exige empresas cada vez mais competitivas exigindo trabalhadores cada vez mais competentes".

Diante disso, constata-se que os saberes em uma sociedade neoliberal se voltam para uma formação que atenda as necessidades advindas do mercado de trabalho. A nova exigência de "produtividade do conhecimento", para Drucker (1997, p. 143), provoca um enorme investimento na educação formal e continuada em pesquisas e produção de novos conhecimentos. O objetivo maior é produzir o conhecimento científico e técnico e transformar tal produto em capital.

Assim, a transferência da burocracia e dos padrões de qualidade total das empresas para o sistema educacional tanto estabelece um ensino em conformidade com os modernos modelos de produção, como fixa uma "nova função" para o professor: "o professor competente, habilidoso", enfim, o "bom professor".

Para Drucker (1997), o professor deve motivar o seu aluno a aprender e a buscar constantemente o conhecimento. Motivá-lo especialmente ao trabalho na sala de aula. Essa motivação tem que ser baseada nos seus "pontos fortes". O aluno precisa adquirir competência mínima em matérias básicas e, nesse processo de aprendizagem, o professor deve corrigir os "pontos fracos" identificados.

Com a demanda do mercado de trabalho por profissionais competentes cabe à instituição de ensino formar pessoas capazes de compreenderem o que fazem para o exercício das novas profissões que vão surgindo. Busca-se a promoção de um conhecimento mais global do indivíduo como elemento necessário para a melhoria da produção.

Para Nunes et al. (2005, p. 1), as políticas de formação de professor no Brasil, implementadas a partir da década de 1990, adotaram a pedagogia das competências como referencial teóricometodológico para "controle, orientação e avaliação da formação de professores e do trabalho docente". O conceito de competência trazido nessas políticas de formação baseia-se na "gestão" ou no "manuseio" 
dos saberes (conhecimento) em diferentes situações que exijam eficiência e eficácia no âmbito laboral e profissional.

Perfila-se, portanto, as competências do futuro professor/trabalhador para organizar o processo produtivo, prevenir as falhas e garantir qualidade em cada etapa. É requerido deste o desenvolvimento do raciocínio analítico, da habilidade e rapidez para processar informação e tomar decisões. Essa tendência ocorre tanto nas características de aprendizagem do estudante como nas atribuições do professor para com a docência.

Dessa forma, o Estado determina padrões de qualidade para as instituições de ensino, os quais se apresentam da seguinte forma: premiam-se as melhores escolas, punem-se as escolas menos produtivas; o ensino procura atender às demandas do mercado de trabalho, a escola escolhe os melhores alunos para o mercado de trabalho, e a responsabilidade financeira da educação é passada para os municípios.

"De fato, por toda parte, é o instrumentalismo estreito que reina, o discurso da adaptação e da utilidade momentânea, enquanto que as questões fundamentais, as que dizem respeito à justificação cultural da escola, são sufocadas ou ignoradas" (FORQUIN, 1993, p. 10).

Entretanto, cabe ainda ao Estado gerir e controlar os critérios de avaliação do sistema educacional, como se revela pelas reformas curriculares, pelos exames do Enem que avaliam o aluno e pela criação do exame em questão que avaliaria o professor a partir de 2011.

\section{A formação inicial do professor como "técnico do ensino"}

É notório afirmar que os progressos científicos e tecnológicos, a partir da década de 1980, no Brasil, transformaram as relações sociais e o trabalho de tal maneira que se presencia uma busca por bens materiais de uma forma nunca antes vista. As palavras de ordem localizam-se nas esferas do poder econômico pelo acúmulo de capital e pela mercantilização da cultura, a saber, da educação. A educação, que é indispensável à vida coletiva do homem, funciona, não obstante, como uma esfera mantenedora da estrutura de classes e cumpre o seu papel de formadora do indivíduo dentro de um determinado contexto histórico.

Neste amplo contexto de inovações e mudanças, a polivalência exigida do trabalhador profissional (re)estabelece os objetivos de formação (adestramento) do indivíduo, direcionando-o ao desenvolvimento de atitudes e de comportamentos padronizados e não-questionáveis. A universidade precisa dar conta de formar um "novo" profissional. As instituições se reorganizam administrativamente e implantam novos currículos acadêmicos voltados ao cumprimento de metas a curto prazo e à formação de sujeitos capazes de lidar com as inúmeras "façanhas" e "desafios" do mercado de trabalho. Decorrentes disso, os programas educacionais vão perdendo gradativamente o caráter crítico da formação acadêmico-universitária.

A universidade vem sofrendo interferências decorrentes de todo esse processo histórico de mudança. Na década de 1970, a universidade teve que se adaptar às exigências do mercado, alterar seus currículos e dirigir-se para uma formação rápida de profissionais requisitados como mão-de-obra qualificada para os postos de trabalho. Na década de 1980, houve a expansão das universidades privadas e a abertura para parcerias entre as instituições públicas de Ensino Superior e as empresas privadas. Cabia às empresas assegurar emprego aos profissionais formados pelas universidades, oferecer estágios acadêmicos e financiar pesquisas voltadas aos seus interesses. Hoje, a universidade, chamada “operacional", encontra-se regida aos moldes de uma organização empresarial.

Com a concentração do trabalho humano na produção massificada de conhecimentos e na aplicação desses para a obtenção de capital pelas 
grandes empresas, o papel do professor se restringe à execução de normas e programas emergenciais para a formação profissional. Segundo Giroux (1997), na prática docente do "técnico de alto nível", que é o professor, exige-se uma pluralidade de conhecimentos instrumentais e pragmáticos no processo de ensino e de aprendizagem.

Pesquisas revelam uma tendência a uma postura pedagógica dos professores universitários voltada para o cumprimento de ementas e execução dos programas de ensino elaborados previamente pelas instituições (MOITALOPES, 1996; WIELEWICKI, 2002). Tendo-se, em mãos, um programa de ensino pre-determinado a ser rigorosamente cumprido, uma metodologia baseada em pesquisas que comprovam sua eficiência para o ensino e aprendizagem de línguas e materiais de ensino "prontos" para o uso, a tarefa dos professores é ensinar com eficiência e qualidade para que o aluno aprenda a língua estrangeira e possa imediatamente ingressar no mercado de trabalho.

A racionalidade técnica e instrumental exige do professor uma formação técnica e especializada para executar procedimentos de conteúdos e instrução predeterminados, legitimando o que Giroux (1997) estabelece como "pedagogias de gerenciamento". As "pedagogias de gerenciamento" consistem em um ensino a partir de "pacotes curriculares" em que "o conhecimento é subdividido em partes diferentes, padronizado para serem mais facilmente gerenciados e consumidos, e medidos através de formas de avaliação predeterminadas" (GIROUX, 1997, p. 160).

Drucker (1997), considerando a época contemporânea "pós-capitalista" e Lyotard (2004), qualificando-a de "idade dita pós-moderna", tratam do fenômeno educativo como "produção material"s, em que as ações educativas realizadas no interior da sala de aula devem dirigir-se a um ensino otimizado e eficiente. $\mathrm{O}$ ensino é visto como extensão da empresa, e cabe às instituições de Ensino Superior formar sujeitos instruídos que sejam capazes de "aprender a aprender", de explorar suas capacidades e de buscar constantemente as competências necessárias às novas funções no âmbito do trabalho. A racionalidade técnica e instrumental exige do professor uma formação técnica e especializada para executar procedimentos de conteúdos e instrução predeterminados, legitimando o que Giroux (1997) estabelece como "pedagogias de gerenciamento".

Essa é uma visão unilateral de formação acadêmica. Os técnicos são formados para o mercado de trabalho; as tecnologias de informação e comunicação, funcionando como meios facilitadores, conduzem o aluno a uma aprendizagem "autônoma" ao mesmo tempo que desincumbem o professor do seu papel exclusivo de educador.

\section{A tentativa de Institucionalização do Instrumento de Avaliação do Professor}

\begin{abstract}
$\mathrm{Na}$ modernidade, confirmou-se uma lógica, uma retórica e uma ideologia. Uma lógica que no campo sociológico se chama capitalismo; no filosófico, positivismo; no religioso, secularização ou profanação do sagrado; no antropológico, homem dimensional como sujeito autônomo e semi-absoluto; no político, Estado da democracia formal para defender a liberdade; no epistemológico, razão instrumental e no científico, primazia da tecnologia que, como manifestação da utilidade das ciências positivas, se colocará acima dos valores morais (MARTIN ROJO, 1998 apud RIOS, 2001, p. 40).
\end{abstract}

\footnotetext{
${ }^{5}$ Saviani (2003, p. 11) diz que a educação é considerada atualmente "o processo de produção material (capital) passando pelo processo não-material, que a subsidia e que a sustenta - produção de habilidades e competências para transformar a produção material. [...] Esse processo de produção da existência humana passa primeiramente pela garantia da subsistência material, por isso, o trabalho material".
} 
Pensar em um instrumento que capture o "bom professor" é tão radical quanto pensar em uma forma de se produzir a exclusão de determinados valores, privilegiando-se uma dimensão técnica que restringe e privilegia apenas o que se convencionou como "bom". Assim, fica de fora o "extraordinário" e tantos outros adjetivos tão necessários à sobrevivência, ao prazer de aprender e descobrir, experiências que não cabem em um adjetivo tão breve.

O caráter inovador da educação escolar por meio da tentativa de institucionalização deste último exame, o "Enem dos professores", está na intenção de se definir "um marco [no sistema educacional brasileiro] para orientar as políticas de seleção, formação, avaliação e desenvolvimento na carreira do magistério" (JARETA, 2011, p. 26).

A busca pela eficiência e produtividade na escola, por meio da incorporação do novo - o referido exame - mostra, mais uma vez, que as políticas educacionais no Brasil, ao longo de sua história, têm tratado de elaborar e instituir novos documentos oficiais (parâmetros e diretrizes) e exames avaliativos que deixem para trás políticas mal sucedidas na expectativa de geração de mudanças na qualidade da educação básica.

O documento "Referenciais para o Exame Nacional de Ingresso na Carreira Docente", que, em nosso entendimento, encontra-se pautado na formação do profissional docente por meio das competências, faz, inicialmente, menção à relevância do papel do professor para uma educação de qualidade conforme podemos verificar a seguir: "São eles que conduzem e mediam o processo de ensino-aprendizagem dos alunos diariamente, e devem receber toda a atenção se, de fato, pretendese buscar um ensino que forme alunos com plena cidadania e igualdade de oportunidades" (INEP, 2010, p. 1).

Machado (2002), afirma que na sociedade neoliberal, recai sobre o trabalhador/professor a responsabilidade pela "produtividade" e "eficiência" do seu trabalho docente, do qual depende, quase que exclusivamente, a qualidade da formação escolar. No item "Garantindo bons professores em cada sala de aula", o documento reforça essa relação de dependência da educação de qualidade nas "boas práticas docentes do professor". Para tanto, o documento afirma que "a prioridade geral dos gestores educacionais deveria ser definir de forma clara e concisa o que se espera em relação aos conhecimentos e habilidades dos professores, ou seja, definir padrões para um bom professor" (INEP, 2010, p. 1).

Como podemos verificar os conhecimentos e habilidades almejados nos professores seguem o intuito de padronizar o "bom" professor, revelamse como uma política educacional pautada na "pedagogia das competências" (NUNES et al., 2005). Em busca dessa padronização da profissão docente por vários países, chegou-se a uma lista com diferentes fatores, citados adiante, os quais, segundo o próprio documento, "ressaltam a importância da valorização da identidade do professor como alguém que necessita de conhecimentos e habilidades específicos para seu exercício profissional" (INEP, 2010, p. 3).

Vinte são os fatores recorrentes entre os países investigados, destacados por seus sistemas educacionais de qualidade (Austrália, Canadá, Cingapura, Chile, Cuba, Estados Unidos e Inglaterra), que caracterizam o "bom" professor:

1. Domina os conteúdos curriculares das disciplinas que leciona, o que inclui a compreensão de seus princípios e conceitos.

2. Conhece as características de desenvolvimento dos alunos, suas experiências e contexto em que vivem, e como esses fatores afetam sua aprendizagem.

3. Domina a didática das disciplinas que ensina, incluindo diversas estratégias e atividades de ensino. 
4. Domina o currículo ou as diretrizes curriculares das disciplinas que leciona.

5. Organiza os objetivos e conteúdos de maneira coerente com o currículo, os momentos de desenvolvimento dos alunos e seu nível de aprendizagem.

6. Seleciona recursos de aprendizagem de acordo com os objetivos de aprendizagem e as características de seus alunos.

7. Seleciona estratégias de avaliação coerentes com os objetivos de aprendizagem, a disciplina que ensina e o currículo, permitindo com que todos os alunos demonstrem o que aprenderam.

8. Estabelece um clima favorável para a aprendizagem, baseado em relações de respeito, equidade, confiança, cooperação e entusiasmo.

9. Manifesta altas expectativas em relação às possibilidades de aprendizagem $e$ desenvolvimento de todos os seus alunos.

10. Estabelece e mantém normas de convivência em sala de aula, de modo que os alunos aprendam a ter responsabilidade pela sua aprendizagem e a dos colegas.

11. Demonstra valores, atitudes $e$ comportamentos positivos e promovem o desenvolvimento deles pelos alunos.

12. Comunica-se efetivamente com os pais de alunos, atualizando-os e buscando estimular o seu comprometimento com o processo de ensino aprendizagem dos alunos.

13. Aplica estratégias de ensino desafiantes e coerentes com os objetivos de aprendizagem e com os diferentes níveis de aprendizado dos alunos.

14. Utiliza métodos e procedimentos que promovem o desenvolvimento do pensamento $e$ da busca independente do conhecimento.

15. Otimiza o tempo disponível para o ensino, garantindo o máximo de aprendizagem de cada aluno durante toda a duração da aula.

16. Avalia e monitora o processo de compreensão e apropriação dos conteúdos por parte dos estudantes.
17. Busca aprimorar seu trabalho constantemente a partir de diversas práticas, tais como: a reflexão sistemática de sua atuação, a auto-avaliação em relação ao progresso dos alunos, as descobertas de pesquisas recentes sobre sua área de atuação, e as recomendações de supervisores, tutores e colegas.

18. Trabalha em equipe com os demais profissionais para tomar decisões em relação à construção elou implementação do currículo $e$ de outras políticas escolares.

19. Possui informação atualizada sobre as responsabilidades de sua profissão, incluindo aquelas relativas à aprendizagem e ao bemestar dos alunos.

20. Conhece o sistema educacional e as politicas vigentes (INEP, 2010, p. 2-3, grifo nosso).

Observamos, em geral, que esses fatores encaminham o professor a uma operacionalidade do trabalho docente de forma instrumental sem deixar de lado as suas aptidões mentais. As tarefas a serem cumpridas por esse trabalhador da educação exigem-lhe um pensar disciplinado e estratégico para uma conduta padronizada. As subjetividades aqui presentes são estrategicamente utilizadas, de modo que o professor aprenda a refletir sobre e para o trabalho na perspectiva de uma educação de qualidade aos moldes, como já nos referimos anteriormente, do sistema fabril.

No entanto, o documento revela que, no Brasil, a profissão docente é carente social e financeiramente. A garantia de "bons" professores, os quais obtenham as competências acima perfiladas requer certa atratividade. O documento destaca que "as formas de seleção e as condições de emprego e trabalho também têm um papel primordial para atrair e manter na carreira do magistério - de preferência por um bom período numa mesma escola - professores bem preparados e motivados a desenvolver um bom trabalho" (INEP, 2010, p. 4). 
Desse modo, objetivando aprimorar os processos de seleção para a carreira docente a fim de atrair "bons" professores, o MEC e o INEP estão desenvolvendo um exame nacional anual aos interessados no ensino, como profissão, com base em temas específicos relacionados a diferentes competências a serem exigidas do candidato:

O Exame terá periodicidade anual, sendo que cada secretaria estadual ou municipal poderá fazer sua adesão, indicando assim aos candidatos que utilizará a nota do Exame como substituta da nota da prova do concurso ou como parte componente dela no seu respectivo concurso de provas e títulos. O candidato participa do Exame $\mathrm{e}$, quando as redes de seu interesse anunciarem que existem vagas de professor a preencher, ele pode enviar sua nota para concorrer a essas vagas com outros candidatos que também terão participado do Exame (INEP, 2010, p. 5).

No processo de avaliação foi levantada uma lista de temas para compor o Exame, cada um, com uma série de "tópicos relacionados às habilidades a serem demonstradas pelos candidatos a professor" (INEP, 2010, p. 6).

Por fim, o documento articula que um exame bem elaborado em termos das competências exigidas do futuro professor, contribui para a qualidade da prática docente e, consequentemente, na educação dos alunos:

“[...] ao promover uma melhoria no instrumento de seleção dos candidatos à docência, o Exame deve promover uma melhoria na qualidade dos professores que ingressarão no magistério, o que fará com que os alunos da educação básica ganhem professores com uma qualificação cada vez melhor" (INEP, 2010, p. 7).

A questão que resiste e ainda segue sem resposta é: apenas selecionar os professores será suficiente para garantir maior qualidade no ensino? Como fica a formação? E as demais estruturas em que a ação pedagógica deve se apoiar para exercer o domínio de todos os conteúdos assinalados no documento?

\section{Considerações Finais}

Passando-se às considerações finais, constatamos que o Exame Nacional para Ingresso na Carreira Docente, em desenvolvimento pelo MEC/INEP, responde diretamente a um profissional fabricado, produzido por meio de padrões e referenciais que o tornam, segundo o documento, um "bom" professor.

Retomando-se as palavras de Forquin (1993), quando assevera que "é o instrumentalismo estreito que reina, o discurso da adaptação e da utilidade momentânea, enquanto que as questões fundamentais, as que dizem respeito à justificação cultural da escola, são sufocadas ou ignoradas" (FORQUIN, 1993, p. 10), percebemos que a educação escolar é dependente de uma educação superior imbuída de ideologias instrumentais, pragmáticas e mercadológicas que enfatizam uma abordagem tecnocrática para a preparação dos professores e também para a pedagogia de sala de aula. Forma-se o "bom" professor como um técnico de alto nível, ou seja, aquele que, mesmo com uma certa autonomia dentro da sala de aula, deve cumprir regras e objetivos decididos por outrem; o professor tem a função de administrar e implementar programas curriculares.

A análise e reflexão desse documento nos revelou que as políticas brasileiras no campo da formação de professores adotam a pedagogia das competências como referencial teórico. Vimos que a inovação aqui se configura na proposta de implantação de um exame que avaliará publicamente as "condições ideais" de "professores competentes" para atuarem nas escolas brasileiras e "transformarem" - como se fossem os maiores responsáveis - o atual quadro da educação. 


\section{Referências}

BRUCE, B. C. Innovation and social change. In: BRUCE, B. C.; PEYTON, J. K.; BATSON, T. W. (org.). Networkbased classrooms: promises and realities. New York, NY: Cambridge University Press, 1993.

CARDoso, S. H. B. Discurso e ensino. Belo Horizonte: Autêntica, 1999.

DRUCKER, P. F. A sociedade pós-capitalista. 6. ed. São Paulo: Pioneira, 1997.

DUARTE, N. Educação escolar, teoria do cotidiano e a escola de Vygotsky. São Paulo: Autores Associados, 2001.

FACCI, M. G. D. Valorização ou esvaziamento do trabalho do professor? Um estudo crítico-comparativo da teoria do professor reflexivo, do construtivismo e da psicologia vigotskiana. Campinas, SP: Autores Associados, 2004.

FORQUIN, J-C. Escola e cultura. Porto Alegre: Artes Médicas, 1993.

GIROUX, H. Os professores como intelectuais. Porto Alegre: Artmed, 1997.

INEP - Instituto Nacional de Estudos e Pesquisas Educacionais Anísio Teixeira. Referenciais para o exame nacional de ingresso na carreira docente. Brasília, DF: INEP, 2010. Disponível em: http://consultaexamedocente. inep.gov.br. Acesso em: 15 jun. 2018.

JARETA, G. Mínimo denominador comum. Revista Educação, São Paulo, SP, 10 set. 2011. Disponível em: https://www.revistaeducacao.com.br/author/gabrieljareta/page/5/. Acesso em: 15 jun. 2018.

KENSKI, V. M. O papel do professor na sociedade digital. In: CASTRO, A. D. de; CARVALHO, A. M. P. de (org.). Ensinar a ensinar. São Paulo: Thomson, 2001. p. 95-106.
LARROSA, J. Pedagogia profana: danças, piruetas e mascaradas. Tradução de Alfredo Veiga-Neto. Porto Alegre: Contrabando, 1998.

LYOTARD, J. F. A condição pós-moderna. 8. ed. Rio de Janeiro: J. Olympio, 2004.

MACHADO, L. A. A institucionalização da lógica das competências no Brasil. Pro- Posições, Campinas, SP, v. 13, n. 1, p. 92-110, jan./abr. 2002.

MARTINS, J. C. Vygotsky e o papel das interações sociais na sala de aula: reconhecer e desvendar o mundo. 1997. online. Disponível em: http://www.crmariocovas. sp.gov.br/pdf/ideias_28_p111-122_c.pdf. Acesso em: 2 out. 2018.

MOITA LOPES, L. P. da. Oficina de lingüística aplicada: a natureza social e educacional do processo de ensino/ aprendizagem de línguas. Campinas, SP: Mercado das Letras, 1996.

NUNES, C. S. C.; MONTEIRO, A. L.; SANTOS, T. R. L.; TÁVORA, M. J. S.; CUNHA, E. R. A pedagogia das competências como política de formação de professores no Brasil. In: CONGRESSO INTERNACIONAL EDUCAÇÃO E TRABALHO, 2005, Aveiro, PT. Anais [...]. Aveiro: Universidade de Aveiro, 2005. v. 1. Tema: Representações sociais, competências e trajectórias profissionais.

RIOS, T. A. Compreender e ensinar: por uma docência da melhor qualidade. São Paulo: Cortez, 2001.

SAVIANI, D. Pedagogia histórico-crítica: primeiras aproximações. 8. ed. Campinas, SP: Autores Associados, 2003.

WIELEWICKI, V. H. G. Literatura e sala de aula: síncopes e contratempos: a agência discente e as literaturas de língua inglesa em cursos de licenciatura em letras. $242 \mathrm{f}$. Tese (Doutorado em Letras) - Faculdade de Filosofia, Letras e Ciências Humanas, Universidade de São Paulo, São Paulo, 2002.

Recebido em: 15 fev. 2019

Aceito em: 10 jun. 2019 
